\title{
Migration of a Dexamethasone Intravitreal Implant to the Anterior Chamber in a Patient with a Intra-Scleral Haptic Fixated Intraocular Lens
}

\author{
Farzad Jamshidi \\ Vinay A Shah \\ Kamran M Riaz (1C)
}

Dean McGee Eye Institute, University of Oklahoma Department of Ophthalmology, Oklahoma City, OK, USA
Correspondence: Kamran M Riaz

Dean McGee Eye Institute, University of Oklahoma Department of

Ophthalmology, 608 Stanton L Young

Blvd, Oklahoma City, 73I04, OK, USA

Tel + I 405-27I-6060

Email Kamran-Riaz@dmei.org
Purpose: To report a case of posterior to anterior migration of a dexamethasone (Ozurdex) implant in a case of scleral-fixated intraocular lens (SFIOL) via Yamane technique.

Methods/Patients: Single case report.

Results: Dexamethasone implant was successfully removed in the operating room. The patient had improved confrontational visual field and did not develop corneal edema nor intraocular pressure elevation.

Conclusion: In the presence of a stable SFIOL via Yamane technique, posterior chamber implants may migrate to the anterior chamber. Clinicians may wish to exercise additional caution in injecting posterior chamber steroid implants in this patient population.

Keywords: dexamethasone implant, intra-scleral haptic fixation, scleral fixated IOL, uveitis, Yamane, ISHF

\section{Introduction}

Several techniques for the surgical management of aphakia have been introduced in recent years. Among these techniques, transconjunctival intra-scleral haptic fixation (ISHF), introduced in 2014 by Yamane, ${ }^{1}$ offers several advantages to traditional scleral-fixated intraocular lenses (SFIOLs) techniques requiring sutures. ${ }^{2,3}$ Many surgeons who perform SFIOL surgery have adopted ISHF as a first-line surgical technique as it is a suture-less, glue-less procedure requiring a small incision with good results worldwide. ${ }^{4}$

While these techniques provide good visual rehabilitation, the stability of the SFIOL complex may not be as secure as compared to an eye with intact capsuleIOL complex. For example, posterior-to-anterior migration of dexamethasone intravitreal implants has been reported in the context of suture fixated SFIOLs. ${ }^{5}$ Schechet et al reported an anterior migration of a retained IOL-optic fragment from the posterior segment in the presence of an ISHF IOL. ${ }^{6}$ Thus, it is possible that despite the lack of significant, appreciable pseudophacodonesis in these eyes, transient shifting or tilting of the SFIOL may create a potential space allowing these implants to migrate into the anterior chamber. To the best of our knowledge, we report the first case of anterior migration of an intravitreal dexamethasone implant in presence of a stable ISHF IOL necessitating surgical removal.

\section{Case Description}

An 87-year-old white male had previously undergone multiple intraocular surgeries for management of glaucoma, corneal edema and cystoid macular edema (CME), 
including ab externo gel stent implant (Xen 45 gel; Allergan, Irvine, CA), descemet's stripping automated endothelial keratoplasty (DSAEK), and previous dexamethasone implants. The patient developed a dislocation of his previous suturedfixated SFIOL and subsequently underwent combined pars plana vitrectomy (PPV), SFIOL removal and placement of new SFIOL via ISHF technique (CT Lucia 602; Zeiss; Ontario, CA, USA). Postoperatively, the patient presented with recurrent-onset CME. Given the patient's favorable response to steroid implants previously, he received an additional intravitreal dexamethasone injection (Ozurdex; Allergan, Irvine, CA) approximately 6 weeks after the ISHF procedure. Three weeks later, he presented emergently with complaints of a sudden-onset inferior visual field deficit. Examination at this time revealed the dexamethasone implant was now located in the anterior chamber with an intact iris-SFIOL complex (Figure 1).

Given the risks of corneal edema and elevated intraocular pressure caused by the dexamethasone implant in the anterior chamber, especially in the presence of previous DSAEK, we elected to proceed with surgical removal of the steroid implant. ${ }^{7}$ The implant broke into several pieces during removal requiring additional care to ensure all pieces were removed without any complications. Postoperative course was uneventful without any corneal edema or elevated intraocular pressure at his three months follow up. The patient continues to receive sub-tenon steroid injection for treatment of his CME.

\section{Discussion}

Intravitreal implants are gaining popularity in treatment of various causes of posterior segment inflammation. ${ }^{8}$

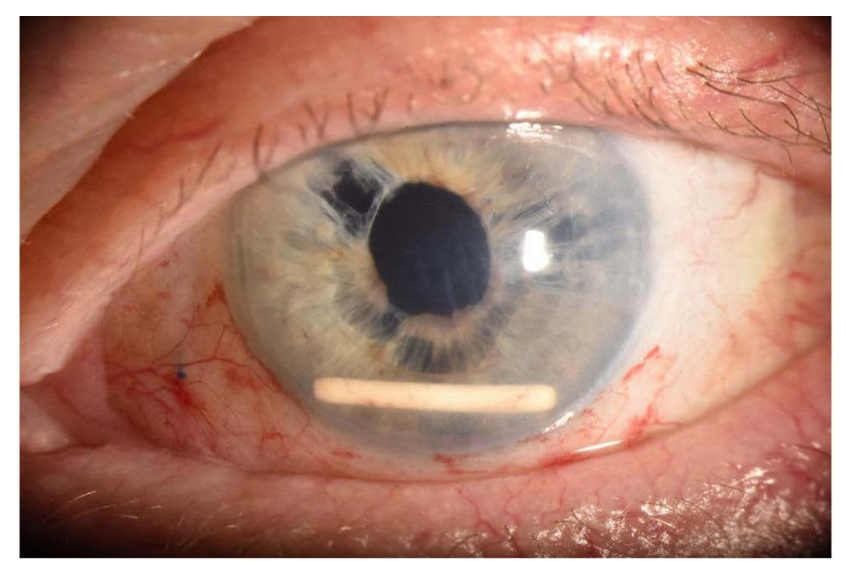

Figure I Dexamethasone implant in the anterior chamber. Note the intrascleral fixated haptics visible nasally. Presence of descemet's folds is suggestive of corneal edema.
Similarly, ISHF continues to gain popularity as a viable technique for the treatment of aphakia among surgeons worldwide. A significant number of these patients may require injection of steroid implants due to concomitant posterior segment pathology. Previous reports have noted the risk of posterior-to-anterior migration of injected implants in the context of sutured SFIOLs. ${ }^{5-7}$ Our patient had anterior migration of a dexamethasone implant placed after ISHF with intact iris complex. We postulate that ISHF IOLs may have similar properties as sutured SFIOLs. This suggests that eyes with ISHF IOLs and SFIOLs, unlike pseudophakic eyes with in-the-bag IOLs, demonstrate a functionally unicameral eye anatomy with posterior to anterior segment connectivity. This unicamerality, which may be transient and caused by factors such as Valsalva maneuvers, head positioning or low gradetrauma, likely arises from the lack of posterior capsular support that creates a potential space for posterior-toanterior migration.

The instability of the ISHF IOL causing this transient, functional unicamerality may have several explanations. First, the original described ISHF technique used an IOL with a 7-mm optic (Santen Pharmaceuticals, Osaka, Japan) which is $1 \mathrm{~mm}$ larger than the 6-mm optic of the CT Lucia 602 IOL used for ISHF. In the United States, ISHF is performed with 3-piece IOLs with 6-mm optics as no larger optic IOL is available for surgery. Thus, it is possible that a smaller optic IOL allows for a larger space between the IOL-iris complex, allowing for anterior migration. Second, given the extensive surgical history in our patient, it is possible that instability of the iris complex (iridodonesis), in the context of valsalva maneuver, may have transiently allowed the steroid implant to migrate around the IOL-iris complex as reported previously. ${ }^{6}$ Third, the effective lens position of ISHF may have been more posterior than appreciated, allowing for a potential space for implant migration. Once passed the IOL complex, the implant could have entered the anterior chamber through the intact pupil, or the area of iris atrophy seen in Figure 1.

We believe our case is instructive for several reasons. First, the unexpected migration of the implant indicates that the ISHF IOL may have instability allowing communication between the posterior and anterior chambers. Second, in the setting of SFIOLs, including ISHF, retina specialists may wish to use other medications to treat posterior segment inflammation and eschew the use of injectable steroid implants. Finally, timely diagnosis and 
surgical intervention may help prevent corneal edema and elevated intraocular pressure. The limitations in our study include report of a single case. However, to our knowledge, this is the first case report of its kind in ISHF (Yamane technique) SFIOLs. With the increasing popularity of the Yamane technique, ${ }^{9}$ we suspect more cases will be noted in the near future.

\section{Conclusion}

In our patient, removal of the migrated dexamethasone implant led to a successful outcome. The patient's confrontational visual field improved and the patient had subjective improvement in vision. Additionally, no corneal edema nor increase in intraocular pressure developed.

This case highlights that similar to sutured SFIOLs, ISHF IOLs are prone to an unexpected migration of intravitreal implants into the anterior chamber. Clinicians may wish to consider alternative treatment strategies to treat posterior segment inflammation in this context. Prompt diagnosis and operative removal of the implant can prevent more serious complications as demonstrated in our case.

\section{Consent Statement}

The patient provided informed written consent for participation in this study as well as publication case details and imaging in scientific journals.

\section{Funding}

This study did not have external funding.

\section{Disclosure}

Dr Vinay A Shah is co-owner of Cloud Nine Development. The authors do not have any other conflicts of interest nor propriety interests associated with this work.

\section{References}

1. Yamane S, Inoue M, Arakawa A, Kadonosono K. Sutureless 27-gauge needle-guided intrascleral intraocular lens implantation with lamellar scleral dissection. Ophthalmology. 2014;121(1):61-66. doi:10.1016/j. ophtha.2013.08.043

2. Malbran ES, Malbran E Jr, Aranguren AN. Scleral-fixated intraocular lenses. Arch Ophthalmol. 1988;106(10):1347-1348. doi:10.1001/ archopht.1988.01060140511008

3. Agarwal A, Jacob S, Kumar DA, Agarwal A, Narasimhan S, Agarwal A. Handshake technique for glued intrascleral haptic fixation of a posterior chamber intraocular lens. J Cataract Refract Surg. 2013;39(3):317-322. doi:10.1016/j.jcrs.2013.01.019

4. Point-counterpoint: Scleral-sutured fixation vs. Yamane technique. Available from: https://www.reviewofophthalmology.com/article/point counterpoint-scleralsutured-fixation-vs-yamane-technique. Accessed December 10, 2020.

5. Kayıkçığlu Ö, Doğruya S, Sarıgül C, Mayalı H, Kurt E. Anterior chamber migration of ozurdex implants. Turk J Ophthalmol. 2020;50 (2):115-122. doi:10.4274/tjo.galenos.2019.43778

6. Schechet SA, Hariprasad SM, Riaz K. Posterior to anterior migration of a large optic fragment in a pseudophakic eye. GMS Ophthalmol Cases. 2020;10:DOC06.

7. Khurana RN, Appa SN, McCannel CA, et al. Dexamethasone implant anterior chamber migration: risk factors, complications, and management strategies. Ophthalmology. 2014;121(1):67-71. doi:10.1016/j. ophtha.2013.06.033

8. London NJ, Chiang A, Haller JA. The dexamethasone drug delivery system: indications and evidence. Adv Ther. 2013;30(6):644. doi:10.1007/s12325-013-0035-2

9. Yamane S, Ito A. Flanged fixation: Yamane technique and its application. Curr Opin Ophthalmol. 2021;32(1):19-24. doi:10.1097/ ICU.0000000000000720

\section{Publish your work in this journal}

The International Medical Case Reports Journal is an international, peer-reviewed open-access journal publishing original case reports from all medical specialties. Previously unpublished medical posters are also accepted relating to any area of clinical or preclinical science. Submissions should not normally exceed 2,000 words or 4 published pages including figures, diagrams and references. The manuscript management system is completely online and includes a very quick and fair peer-review system, which is all easy to use. Visit http://www.dovepress.com/testimonials.php to read real quotes from published authors. 